\title{
ANALISIS KELAYAKAN PENGEMBANGAN PROYEK APARTEMEN CITRA LIVING CITRA GARDEN CITY
}

\author{
Citra Sari Kusuma Wardhani \\ Program Studi Magister Manajemen Universitas Tarumanagara \\ citra_pi87@yahoo.com \\ Yanuar \\ Program Studi Magister Manajemen Universitas Tarumanagara
}

\begin{abstract}
Jakarta is experiencing a favourite residential growth due to the high level of urban migration to Indonesia's capital. Therefore, PT CD, through its subsidiary, PT CMG, KSO, tries to fulfill the increasing demand of residential housing by developing a \pm 1 ha of land in the West of Jakarta. The development is called the Apartement Citra Living project. This paper is developed to determine the feasibility of the project through cash flow sensitivity analysis. There are 2 (two) assumptions used, which are : the normal, and optimistic assumptions. These assumptions are tested through 4 (four) calculation methods: Payback Period, Net Present Value (NPV), Internal Rate of Return (IRR) and Profitability Index (PI). The results of the sensitivity analysis are as follows Payback periods for the project are 8 months for normal and, 3 months for optimistic; The NPV is positive for all assumptions; The IRR for the normal and optimistic assumptions are higher than the Weighted Average Cost of Capital (WACC) 10\%. The PI for normal and optimistic assumptions are more than 1 (one). So, the project is feasible. Therefore, based on the results of the sensitivity analysis of the project's cash flow, it is concluded that the Apartement Citra Living project is a profitable business decision. To increase profitability level, the company should try to find other financing alternatives to lower the cost of capital.
\end{abstract}

Keywords : Payback period, Net Present Value, Internal Rate of Return, Profitability Index

\begin{abstract}
Abstrak : Perkembangan penduduk yang pesat di Jakarta karena faktor urbanisasi menyebabkan permintaan akan kebutuhan tempat tinggal meningkat. Sehingga situasi ini dilihat oleh PT CD untuk mengembangkan bisnis apartemen. PT CD melalui anak perusahaannya PT CMG, KSO mencoba mengembangkan suatu lahan kosong seluas \pm 1 ha di wilayah Jakarta Barat dan lahan ini diberi nama Apartemen Citra Living. Sebelum melakukan pembangunan proyek, maka perlu dilakukan studi kelayakan dengan perumusan strategi dan analisis terhadap faktor-faktor yang berpengaruh dalam perkembangan perusahaan baik internal maupun eksternal sehingga dapat membuat keputusan yang tepat. Perlu dilakukan peninjauan dari sisi cashflow perusahaan untuk melakukan ekspansi. Analisis keputusan investasi dilakukan dengan melakukan uji sensitivity analisis, target penjualan dibuat menjadi 2 alternatif yaitu : alternatif Normal dan alternatif Optimis. Selanjutnya analisis keputusan investasi dilakukan dengan menggunakan 4 (empat) metode yaitu Payback Period, NPV (Net Present Value), IRR (Internal Rate of Return) dan PI (Profitability Index). Dari hasil metode penelitian yang telah dilakukan diperoleh hasil payback period normal 8 bulan dan optimis 3 bulan; , Net Present Value (NPV) positif, Internal Rate of Return (IRR) lebih besar dari WACC 10\% , Profitability Index (PI) lebih dari satu maka proyek Apartemen Citra Living ini dianggap layak dan menguntungkan tidak hanya pihak developer tetapi juga konsumen yang membeli rumah di proyek tersebut untuk dilaksanakan. Dan saran dari penulis adalah melakukan pengecekan kembali terhadap cashflow dengan mempertimbangan pencarian alternatif pendanaan dengan pinjaman yang ditingkatkan sehingga cost of capital kecil.
\end{abstract}


Kata kunci : Payback period,Net Present Value,Internal Rate of Return, Profitability Index

\section{PENDAHULUAN}

Jakarta sebagai Ibukota Negara Indonesia dan merupakan kota metropolitan di Indonesia, dimana pusat bisnis, politik dan kebudayaan ada disini. Tingkat kebutuhan akan hunian yang semakin meningkat namun persediaan tanah yang terbatas, harga tanah yang cukup tinggi dan lokasi tanah yang tidak memungkinkan untuk pembangunan rumah besar, sehingga memanfaatkan tanah yang kecil untuk dipergunakan seefektif dan seefisien mungkin untuk menyelesaikan permasalahan tersebut. Penyelesaian permasalahan dengan efisiensi pemanfaatan lahan yaitu dengan membangun tempat tinggal (terdiri atas kamar tidur, kamar mandi, dapur, dan sebagainya) yang berada pada satu lantai bangunan bertingkat yang besar dan mewah, dilengkapi dengan berbagai fasilitas (kolam renang, pusat kebugaran, toko, dan sebagainya) yang dikenal dengan sebutan Apartemen.

Karena permintaan akan kebutuhan tempat tinggal yang meningkat di jakarta inilah penulis dalam tesis ini ingin melakukan suatu analisis awal, dalam rangka pemenuhan kebutuhan akan tempat tinggal yang dapat membantu pengambilan keputusan investasi dibidang pengembangan atau pembangunan kawasan hunian apartemen kelas menengah diwilayah Jakarta Barat. Analisis awal ini merupakan suatu studi kelayakan pengembangan kawasan yang menentukan apakah gagasan bisnis ini bisa dipertimbangkan dan layak untuk dilaksanakan.

\section{Pokok Masalah}

Dalam tesis ini penulis akan mengulas mengenai strategi yang akan dilakukan oleh PT. CGC melalui anak perusahaannya PT. CMG, KSO dalam rangka pembukaan lahan baru seluas \pm 1 ha untuk pengembangan kawasan hunian beserta fasilitas pendukungnya di daerah Kalideres di Jakarta Barat sebagai wujud ekspansi perusahaan dalam pengembangan unit usahanya. Proyek ini dinamakan proyek Apartemen Citra Living. Dilihat dari kondisi lingkungan dimana lokasi projek berada dikelilingi oleh banyak kompetitor, tentu akan menyebabkan adanya suatu rencana dan strategi pengembangan proyek yang matang dari PT. CMG, KSO dalam menghadapi persaingan di bisnis pengembangan properti.

Masalah yang akan dibahas dalam penulisan ini adalah:

a. Bagaimana menyusun analisis aspek keuangan (finansial), sehingga proyek ini layak untuk dilaksanakan?

\section{Tujuan Penelitian}

Dengan latar belakang sebagaimana telah diuraikan diatas, maka tujuan penulisan ini adalah untuk mengetahui lebih lanjut serta mengidentifikasi faktor-faktor yang penting yang mempengaruhi kelayakan proyek, agar strategi yang dilakukan untuk pengembangan hunian baru ini bisa terwujud dengan cara :

a. Menyusun strategi manajemen proyek yang baku mulai dari tahap perencanaan proyek sampai dengan menyusun peraturan perusahaan dan sumber daya manusia yang akan terlibat dalam pengembangan proyek ini.

b. Melakukan analisis Pemasaran, survey kompetitor dan area target market untuk mengetahui prospek dan daya beli konsumen, sehingga produk yang akan ditawarkan sesuai dengan kemampuan konsumen dalam menyerapnya.

c. Membuat analisis keuangan mulai dari menentukan target sales bulanan dan tahunan, membuat arus kas (cash flow) dan hasilnya dianalisis untuk mengetahui kelayakan investasi bisnis yang akan dikembangkan, tidak hanya pada saat pembangunan tetapi juga saat dioperasionalkan secara rutin mampu mencapai keuntungan yang maksimal 


\section{LANDASAN TEORI}

Apartemen merupakan tempat tinggal suatu bangunan bertingkat yang lengkap dengan ruang duduk, kamar tidur, dapur, ruang makan, jamban, dan kamar mandi yang terletak satu lantai, bangunan bertingkat yang terbagi atas beberapa tempat tinggal. (Kamus Umum Indonesia, 1994, p:69). Ada beberapa hal yang membedakan antara apartemen satu dengan apartemen lain antara lain dapat dilihat dari tinggi bangunan, tampak depan bangunan, stuktur yang digunakan, fasilitas yang ditawarkan, letak lokasi dan kelas apartemen tersebut

Menurut Kasmir dan Jakfar (2010) studi kelayakan bisnis adalah suatu kegiatan yang mempelajari secara mendalam tentang suatu kegiatan atau usaha yang akan dijalankan,untuk menentukan layak atau tidaknya suatu bisnis dijalankan.

Dalam suatu perekonomian yang kompleks sekarang ini, orang harus mau menghadapi tantangan dan risiko untuk mengkombinasikan tenaga kerja, material, modal dan manajemen secara baik sebelum memasarkan suatu produk. Sebuah rencana investasi seharusnya diawali dengan suatu evaluasi kelayakan terhadap rencana investasi itu. Investasi yang memiliki resiko besar seharusnya didahului oleh suatu studi kelayakan.

Aspek-aspek Studi Kelayakan Bisnis Belum ada keseragaman mengenai apa saja yang harus dikaji tergantung dari jenis bisnis yang akan dikembangkan. Proses analisis setiap aspek saling berketerkaitan antara satu aspek dengan aspek lainnya, sehingga hasil analisis aspekaspek tersebut saling terintegrasi. Beberapa aspek kelayakan bisnis adalah aspek pasar, aspek pemasaran, aspek keuangan, aspek teknis dan teknologi, aspek manajemen, aspek SDM, aspek hukum.

\section{METODOLOGI PENELITIAN}

Apartemen Citra Living mengusung konsep green urban living. Dimana memakai material yang ramah lingkungan seperti low energy sun glass window yang mampu menurunkan suhu dari luar dan pemakaian cat dinding dengan green label dimana mampu menahan sinar UV, serta sejalan dengan program Eco Culture yang dicanangkan CR untuk budaya peduli lingkungan khususnya penerapan green building. Apartemen Citra Living termasuk kelas apartemen High-rise dimana akan dibangun 3 tower yaitu Tower A, Tower B dan Tower $\mathrm{C}$ dengan ketinggian diatas 10lantai. Dan untuk pembahasan jurnal ini yang di bahas adalah Tower $\mathrm{C}$

Tower $\mathrm{C}$ akan dibangun 9lantai dengan jumlah unit 198unit dengan 3 tipe yaitu studio, 1 bedroom, dan 2bedroom. Pemasaran proyek ini diproyeksikan untuk 2 tahun yang akan dimulai bulan Januari 2021 sampai dengan akhir tahun 2022, yang dibagi dalam 3 (tiga) kegiatan yaitu :

1. Pengurusan Perijinan, legalitas dan persiapan desain

2. Development (pembangunan sarana dan prasarana)

3. Construction (pembangunan unit apartemen)

Dalam rangka melakukan uji sensitivity analisis, target penjualan akan dibuat dengan dua alternatif :

1. Target penjualan Normal yaitu pada tahun 2021 sebesar $44 \%$, tahun 2022 sebesar $56 \%$.

2. Target Penjualan Optimis yaitu pada tahun 2021 sebesar 65\%, tahun 2022 sebesar $35 \%$.

\begin{tabular}{|l|c|c|c|c|}
\hline \multicolumn{1}{|c|}{ Normal } & Modal 2020 & $\mathbf{2 0 2 1}$ & $\mathbf{2 0 2 2}$ & Total \\
\hline & & $57,170,400,000$ & $75,118,680,000$ & $\mathbf{1 3 2 , 2 8 9 , 0 8 0 , 0 0 0}$ \\
\hline Revenue & & & & \\
Cash Outflow & $10,406,062,248$ & $41,500,583,459$ & $62,250,875,188$ & $\mathbf{1 1 4 , 1 5 7 , 5 2 0 , 8 9 4}$ \\
\hline Surplus/Defisit & $(10,406,062,248)$ & $15,669,816,541$ & $12,867,804,812$ & $\mathbf{1 8 , 1 3 1 , 5 5 9 , 1 0 6}$ \\
\hline
\end{tabular}




\begin{tabular}{|l|c|c|c|c|}
\hline \multicolumn{1}{|c|}{ Optimis } & Modal 2020 & $\mathbf{2 0 2 1}$ & $\mathbf{2 0 2 2}$ & Total \\
\hline Revenue & & $83,995,200,000$ & $46,952,640,000$ & $\mathbf{1 3 0 , 9 4 7 , 8 4 0 , 0 0 0}$ \\
\hline & & & & \\
Cash Outflow & $10,406,062,248$ & $40,979,871,859$ & $61,469,807,788$ & $\mathbf{1 1 2 , 8 5 5 , 7 4 1 , 8 9 4}$ \\
\hline & & & & \\
Surplus/Defisit & $(10,406,062,248)$ & $43,015,328,141$ & $(14,517,167,788)$ & $\mathbf{1 8 , 0 9 2 , 0 9 8 , 1 0 6}$ \\
\hline
\end{tabular}

Tabel Proyeksi Cash Revenue Alternatif Normal dan Optimis

Dan biaya dalam pengembangan ini meliputi biaya Devcost sebesar Rp 15.148.488.854; Const Cost sebesar Rp 64.897.322.274 dan Overhead Cost (Marketing promotion 2\%, Third party commision $3.5 \%$, Overhead $4.5 \%$ )

\begin{tabular}{|l|r|r|}
\hline Description & \multicolumn{1}{|c|}{ Normal } & \multicolumn{1}{c|}{ Optimis } \\
\hline Cost Outflow & & \\
Land Acquisition & $26,457,816,000$ & $26,189,568,000$ \\
Const. Cost & $64,897,322,274$ & $64,897,322,274$ \\
Dev. Cost & $15,148,488,954$ & $15,148,488,954$ \\
Overhead \& Marketing Cost & $4,346,666,667$ & $3,346,666,667$ \\
Tax & $3,307,227,000$ & $3,273,696,000$ \\
\hline Total Cost & $\mathbf{1 1 4 , 1 5 7 , 5 2 0 , 8 9 4}$ & $\mathbf{1 1 2 , 8 5 5 , 7 4 1 , 8 9 4}$ \\
Total Revenue & $\mathbf{1 3 2 , 2 8 9 , 0 8 0 , 0 0 0}$ & $\mathbf{1 3 0 , 9 4 7 , 8 4 0 , 0 0 0}$ \\
Total Profit & $\mathbf{1 8 , 1 3 1 , 5 5 9 , 1 0 6}$ & $\mathbf{1 8 , 0 9 2 , 0 9 8 , 1 0 6}$ \\
Profit & $\mathbf{1 4 \%}$ & $\mathbf{1 4 \%}$ \\
\hline
\end{tabular}

Tabel Profit untuk Alternatif Normal dan Optimis Proyek Apartemen Citra Living

Dari tabel summary diatas terlihat bahwa pengembangan Proyek memperoleh presentase profit yang besar yaitu alternatif 1 Normal 14\%, dan alternatif 2 Optimis $14 \%$

Proyek Apartemen Citra Living dianalisis mengunakan 4 metode penelitian investasi yang dipakai yaitu Payback Period Method, Net Present Value (NPV), Internal Rate of Return (IRR), Profitability Index (PI)

\section{Payback Period Method}

Dalam analisis ini, PT CMG, KSO menetapkan selama 2tahun selama pembangunan proyek atau sampai pada penjualan seluruh produk. dari modal sendiri. Dengan perhitungan di atas, payback period untuk Alternatif 1 Normal ini adalah 8 bulan, untuk Alternatif 2 Optimis adalah 3 bulan. Semua hasil ini masih lebih kecil dari ketetapan manajemen yang 2 tahun, dengan demikian proyek ini layak diterima.

\section{Net Present Value (NPV)}

Untuk menghitung NPV, penulis menggunakan asumsi tingkat bunga yang diperoleh dari Bank sebesar 5\%, dan tingkat bunga Kebijakan pemegang saham terhadap modal sendiri sebesar 10\% maka Weighted Average Cost Of Capital (WACC) yang ditetapkan pada perhitungan NPV sebesar 10\% karena proyek ini 100\% menggunakan modal sendiri. Sehingga didapat Alternatif 1 Normal = Rp. 13,157,977,226,- dan Alternatif 2 Optimis = Rp. $15,182,838,353,-$ Artinya menurut penilaian NPV bahwa proyek ini dianggap cukup layak untuk dilaksanakan dengan alternatif terbaik adalah skenario normal dikarenakan akan ada kenaikan harga jual. 


\section{Internal Rate of Return (IRR)}

Metode ini digunakan untuk mencari tingkat bunga yang menyamakan nilai sekarang dari arus kas yang diharapkan di masa datang, atau penerimaan kas, dengan mengeluarkan investasi awal. Dari hasil nett cashflow yang ada didapat IRR untuk Alternatif 1 Normal = $110 \%$ dan Alternatif 2 Optimis $=276 \%$. IRR alternatif 1 dan 2 lebih besar dari Weighted Average Cost Of Capital (WACC), sehingga layak dilaksanakan

\section{Profitability index $(P I)$}

Profitability Index dapat dihitung dengan membandingkan antara PV kas masuk (cash inflow) dengan PV kas keluar (cash outflow). Maka perhitungan dari indeks kemampulabaan / profitability index $(\mathrm{PI})$ untuk Alternatif Normal $=1.16$ dan optimis $=1.16$ Hasil di atas menunjukkan bahwa semua PI lebih besar dari 1 (satu), hal ini berarti bahwa investasi pada proyek ini layak untuk dilaksanakan.

Dari beberapa analisis penilaian investasi dengan perhitungan Payback Periode, Net Present Value, Internal Rate of Return dan Profitability Index, kesemuanya menunjukkan bahwa investasi PT CMG, KSO dalam rangka Pengembangan Apartemen Citra Living di wilayah Jakarta Barat ini dianggap sangat layak untuk dilaksanakan.

\section{SARAN}

Dari aspek marketing perlu melakukan "market survey" untuk menentukan positioning proyek dan target market.

Dari aspek teknik, harus mampu memberikan nilai tambah pada produk bangunan yang dihasilkannya.

Dari aspek keuangan, melakukan pengecekan kembali terhadap cashflow yang sudah dibuat disesuaikan dengan strategi pemasaran, pencarian alternatif pendanaan dan monitoring efisiensi pengeluaran biaya-biaya yang muncul selama proyek berjalan

\section{DAFTAR PUSTAKA}

Suwarsono, Suad Husnan, "Studi Kelayakan Proyek", Unit Penerbit dan Percetakan AMP YKPN, Jogjakarta, 2000.

Umar, Husein, "Studi Kelayakan Bisnis - Teknik menganalisis kelayakan rencana bisnis secara komprehensif", 2nd edition, Gramedia Pustaka Utama, Jakarta, 2003.

Van Horne, James C., et al., "Prinsip-prinsip Manajemen Keuangan", 9th edition, terjemahan Heru Sutojo, Salemba Empat, Jakarta, 1997.

Akmal, Imelda, "Menata Apartemen" Gramedia Pustaka Utama, Jakarta, 2007.

Martin, Scott Jr, "Basic Financial Management" $7^{\text {th }}$ edition, Prentice Hall International, Inc, New Jersey, 1999.

Garrison Noreen, Managerial Accounting, Tenth Edition, Mc Graw-Hill Irwin, 2003. 